\title{
Tampa Scale of Kinesiophobia for Heart Turkish Version Study: cross-cultural adaptation, exploratory factor analysis, and reliability
}

This article was published in the following Dove Press journal:

Journal of Pain Research

23 June 2016

Number of times this article has been viewed

\section{Serap Acar' \\ Sema Savci' \\ Pembe Keskinoğlu ${ }^{2}$ \\ Bahri Akdeniz ${ }^{3}$ \\ Ebru Özpelit ${ }^{3}$ \\ Buse Özcan Kahraman' \\ Didem Karadibak' \\ Can Sevinc ${ }^{4}$}

'School of Physical Therapy and Rehabilitation, ${ }^{2}$ Department of Biostatistics, Faculty of Medicine, ${ }^{3}$ Department of Cardiology, Faculty of Medicine, ${ }^{4}$ Department of Chest Disease, Faculty of Medicine, Dokuz Eylul University, İzmir, Turkey
Correspondence: Serap Acar School of Physical Therapy and Rehabilitation, Dokuz Eylul University, 35340 İnciralti, İzmir, Turkey

Tel +905054933762

Fax +90232 4I24946

Email acarserap2@gmail.com
Purpose: Individuals with cardiac problems avoid physical activity and exercise because they expect to feel shortness of breath, dizziness, or chest pain. Assessing kinesiophobia related to heart problems is important in terms of cardiac rehabilitation. The Tampa Scale of Kinesiophobia Swedish Version for the Heart (TSK-SV Heart) is reliable and has been validated for cardiac diseases in the Swedish population. The aim of this study was to investigate the reliability, parallel-form validity, and exploratory factor analysis of the TSK for the Heart Turkish Version (TSK Heart Turkish Version) for evaluating kinesiophobia in patients with heart failure and pulmonary arterial hypertension.

Methods: This cross-sectional study involved translation, back translation, and cross-cultural adaptation (localization). Forty-three pulmonary arterial hypertension and 32 heart failure patients were evaluated using the TSK Heart Turkish Version. The 17-item scale, originally composed for the Swedish population, has four factors: perceived danger for heart problem, avoidance of exercise, fear of injury, and dysfunctional self. Cronbach's alpha (internal consistency) and exploratory factor analysis were used to assess the questionnaire's reliability. Results of the patients in the 6-minute walk test, International Physical Activity Questionnaire, and Nottingham Health Profile were analyzed by Pearson's correlation analysis with the TSK Heart Turkish Version to indicate the convergent validity.

Results: Cronbach's alpha for the TSK Heart Turkish Version was 0.75, indicating acceptable internal consistency. Although exploratory factor analysis showed a different subgroup distribution than the original questionnaire, the model was acceptable for the four-factor model hypothesis. Therefore, the questionnaire was rated as reliable.

Conclusion: These results supported the reliability of the TSK Heart Turkish Version. Since the acceptable four-factor model fits the subgroups and measures of reliability are sufficiently high, the questionnaire seems reliable for pulmonary arterial hypertension and heart failure patients. Keywords: heart failure, pulmonary arterial hypertension, Tampa Scale of Kinesiophobia, fear of movement, kinesiophobia

\section{Introduction}

In recent years, secondary prevention programs focusing on physical activity and cardiac rehabilitation have been widely used to prevent all cardiac-related causes of mortality and morbidity. ${ }^{1}$ However, poor participation and adherence to the programs are growing problems for this population because of limited daily life activities. ${ }^{2}$ Worsening disease symptoms cause fear of movement and avoidance, resulting in activity limitation. ${ }^{3}$ Most pulmonary arterial hypertension and heart failure patients 
are fearful of being physically active because they anticipate shortness of breath, dizziness, or chest pain. Thus, in the long term, limited physical activity may result in negative physical and psychosocial consequences. ${ }^{4,5}$

The term "kinesiophobia", or the fear of movement, was first introduced in 1990 by Kori et al $^{6}$ in the context of lower back pain in order to assess musculoskeletal pain. They defined kinesiophobia as "an excessive, irrational, and debilitating fear of movement and activity resulting from a feeling of vulnerability to painful injury or re-injury". They developed the Tampa Scale of Kinesiophobia (TSK), a 17-item scale to assess kinesiophobia. This scale has been translated into several languages, including Turkish, ${ }^{7}$ and checked for reliability and validity. ${ }^{8-10}$ The TSK was later adapted for cardiac diseases by Bäck et $\mathrm{al}^{1}$ and designated the TSK Swedish Version for the Heart (TSK-SV Heart). The TSK-SV Heart includes the following constructs: perceived danger for heart problem, avoidance of exercise, fear of injury, and dysfunctional self based on the original framework by Kori et al. The TSK-SV Heart has been found to be reliable and valid for heart diseases.

There is a widespread awareness among researchers on the importance of kinesiophobia assessment related to serious cardiac diseases. Therefore, the aims of this study were 1) to perform a translation and cross-cultural adaptation of the TSK-SV Heart among patients with cardiac disease (pulmonary hypertension and heart failure), to investigate the scale's validity, and to conduct exploratory factor analysis (confirmatory factor analysis has been done previously in other languages) with responsiveness within a Turkish-speaking population sample and 2) to identify the presence of kinesiophobia in Turkish patients with pulmonary hypertension and heart failure.

\section{Methods Subjects}

Forty-three pulmonary arterial hypertension patients and 42 heart failure patients (total 85 patients) who regularly attended the cardiology clinic were enrolled in the study between September 2013 and December 2013. The inclusion criteria were as follows: being followed regularly for pulmonary arterial hypertension or heart failure, sound performance in speech production and fluency in reading, being diagnosed at least 3 months earlier, age between 18 years and 85 years, and volunteering to participate in the study. Patients with neuromusculoskeletal problems induced during physical activity or exercise were excluded from the study. Sociodemographic and clinical characteristics including age, sex, height, weight, body mass index, clinical disease type, and medication information were recorded, after which the assessment battery was applied.

\section{Procedure and measurement}

This cross-sectional methodological study involved translation, back translation, and cross-cultural adaptation, that is, localization. To assess the questionnaire's reliability, Cronbach's alpha (for internal consistency) and exploratory factor analysis were conducted. To indicate the convergent validity, Pearson's correlation analysis was performed with the 6-minute walk test (6MWT), the international physical activity questionnaire (IPAQ), and the Nottingham Health Profile (NHP), for which reliability and validity studies have been conducted in the Turkish-speaking population.

\section{Kinesiophobia}

The original TSK was created by Kori et $\mathrm{al}^{6}$ in 1991 but was not published until 1995. The TSK contains 17 items related to fear of movement and reinjury. The scale also includes work-related injuries in addition to repetitive strain injuries, reinjury, and fear avoidance parameters. The scale was initially applied to the Turkish population by Tunca Y1lmaz et al in $2011 .^{7}$ The test-retest validity was evaluated by intraclass correlation coefficient (95\% CI: 0.720-0.8675), where five items had to be adjusted to the Turkish language.

The TSK-SV Heart comprises 17 statements that assess the subjective rating of kinesiophobia in terms related to cardiac conditions. The statements are rated from "strongly disagree" (score 1) to "strongly agree" (score 4) on a fourpoint Likert scale. Four items $(4,8,11$, and 12) are reverse coded. The total score varies between 17 and 68, with higher values indicating more severe kinesiophobia. The original heart-specific TSK consisted of four subgroups: avoidance of exercise, fear of injury, dysfunctional self, and perceived danger for heart problem based on the original work by Kori et al. ${ }^{6}$ The intraclass correlation coefficient was rated 0.83 , and Cronbach's alpha was 0.78 for this scale.

\section{Convergent validity}

Convergent validity is the principle that measures of theoretically similar constructs should be highly intercorrelated. The convergent validity of two similar constructs can be estimated using correlation coefficients. To test the hypothesis for convergent validity for the TSK Heart, we used the 6MWT, IPAQ, and NHP. Sample size was determined by the number of items on the TSK Heart, and convergent validity in patients with heart failure and pulmonary hypertension was 
evaluated by investigating correlations between the scale's psychometric parameters and the commonly used assessments NHP, IPAQ, and 6MWT.

\section{Six-minute walk test}

During the test, patients walked along a $30 \mathrm{~m}$ corridor as fast as possible; patients were informed that they could rest during the test if they felt breathlessness. The 6MWT was applied according to ATS Guideline Statements. ${ }^{11}$

\section{Physical activity level}

Physical activity level was assessed according to the IPAQ, which assesses activity at low, moderate, and high levels. The short form of the IPAQ includes seven items that identify the frequency (times per week) and duration (minutes or hours per day) of different levels of physical activity (walking, moderate activity, and vigorous activity) performed in the previous 7 days. Time spent in sitting is addressed in a separate item. The total score is the sum of the time spent in these activities. Based on the metabolic equivalent (MET) scores of each activity type, the resulting MET-minute per week value can be used to categorize overall physical activity level as inactive $=1$, minimally active $=2$, or very active $=3$. In this study, MET values were calculated after completing the scale. Values up to 600 METs indicate low-level physical activity such as 3-4 mph treadmill walking, values between 600 and 1,300 METs indicate moderate physical activity such as 5-6 mph treadmill walking, and values between 1,300 and 2,000 METs or over indicate high-level physical activity such as jogging on treadmill at $7 \mathrm{mph}$. The reliability and validity of the IPAQ Turkish Version were established by Sağlam et al in $2010 .{ }^{12}$

\section{Nottingham Health Profile}

The NHP is a generic quality of life scale assessing perceived health problems and the effects of these problems on normal daily activities. The questionnaire consists of 38 items divided into six domains: physical mobility (eight items), pain (eight items), sleep (five items), energy (three items), social isolation (five items), and emotional reactions (nine items). Each domain is independently scored from 0 to $100 .^{13,14}$ The reliability and validity of the NHP Turkish Version were determined by Küçükdeveci et al in 2000. ${ }^{15}$

\section{Translational and cross-cultural adaptation}

The process of translation and cross-cultural adaptation, that is, localization, was carried out according to Beaton's guidelines. ${ }^{16,17}$
- Step 1. Translation into Turkish: the TSK Heart was translated from English into Turkish in accordance with Newmark's concept of "communicative translation" to achieve a dynamic equivalence between the source and target texts. "Communicative translation attempts to produce in its readers an effect as close as possible to that obtained on the readers of the original."18 The text was independently translated by two native Turkish speakers, one of whom was a linguist and the other a health care professional, who knew English as a second language. Finally, both target texts were compared for equivalent effect, and a single version was agreed upon.

- Step 2. Back translation into English: two bilingual translators with English as a first language back translated the agreed Turkish version into English taking into account cultural adaptation, that is, the localization process. They compared the two versions and agreed on a single version.

- Step 3. Review committee: the final version was submitted to a bilingual committee consisting of clinicians and translators. The text was checked for semantic and idiomatic equivalence acceptable for dynamic equivalence. Step 3 ended with a final approval.

- Step 4. Test of the prefinal version: the prefinal version was sent to the authors of the original form, and their comments were taken into consideration. Then, the final version was piloted with 30 patients by testing what was meant by each item and response chosen in order to verify whether the formulation of the item was clear or not. All of the findings were reevaluated by the expert committee. Finally, the back translation of the scale was approved by the author who composed the original form.

\section{Evaluation of the scale \\ Reliability}

Cronbach's alpha was initially assessed for the whole scale. The resulting value of 0.64 was too low for the health context, so the items affecting reliability were identified and excluded using the "alpha if item deleted" procedure. The reliability analysis was repeated, and Cronbach's alpha was estimated with this procedure. Several authors reported that first removing reverse-coded items, resulting in an eleven-item scale (titled the TSK-11), improved the psychometrics. Thus, applying the "if item deleted" procedure improved Cronbach's alpha to 0.79 and the intraclass correlation coefficient to 0.759 , indicating a moderately significant correlation. ${ }^{19}$ In this study, a Cronbach's alpha value of $<0.70$ for the whole scale was achieved by extracting some items. 
Test-retest measurements were analyzed by asking the patients to repeat the questionnaire after a period of at least 7 days. Following assessment of item-total correlation, test-retest agreement was determined by comparing initial and retest scores. Tukey's test of additivity works on the principle of additivity. Therefore, although ordinal scales are usually evaluated using nonparametric tests, due to the additive nature of this scale, the analyses in our study were done with parametric tests. Thus, the variables used to assess convergent validity were adjusted for the Pearson's correlation coefficient. ${ }^{20}$ The variables used in the Pearson's correlation test for convergent validity were IPAQ, NHP, and 6MWT distance values.

\section{Exploratory factor analysis for covariance or correlation matrix}

The Kaiser-Mayer-Olkin (KMO) statistic is a measure of sampling adequacy, both overall and for each variable. The overall KMO is printed in the "KMO and Bartlett's Test" table of the factor output. The measures of sampling adequacy for individual variables are printed as the diagonal elements of the anti-image correlation matrix in the "Anti-image Matrices" table of the factor output. ${ }^{21-23}$

An appropriate correlation matrix for factor extraction is a table with moderate correlations between the variables. Variables' absolute coefficients and correlation coefficients should have a minimum correlation of 0.30 between the variables. This was analyzed by calculating the KMO, which was determined as $>0.6$ by Bartlett's test, and KMO indicated sample adequacy. Thus, we are able to conclude that factor extraction was possible for correlation. Factor components were between 0.40 and $0.79 .^{20}$

\section{Ethical considerations for the study}

The study was approved by the Dokuz Eylul University Medical Ethics Committee, and the patients gave their written informed consent to take part in the research prior to the study. Maria M Back, the creator of the original TSK, was asked for permission to apply the scale in a convergent validity study for the Turkish language. Similarly, the sample size of cardiac patients in this study was based on its original form because the scale's number of questions is five to ten times reasonable when determining the sample size of the patients. In addition, during the ethical considerations, the Head of the Dokuz Eylul University Faculty of Medicine, Department of Cardiology, approved the study to be held in their department.

\section{Results}

Forty-six male (55.4\%) and 37 female (44.6\%) cardiac patients (43 with pulmonary arterial hypertension and 32 with heart failure) with a mean age of $55 \pm 14.9$ years were enrolled in the study. Demographic and clinical data related to the patients are given in Table 1.

To evaluate the scale's reliability, internal consistency was assessed using Cronbach's alpha. For acceptable reliability, the Cronbach's alpha of the full questionnaire should be $>0.70$. In our study, the internal consistency coefficient for the complete 17-item TKS Heart revealed low reliability across items, with a Cronbach's alpha of 0.640. In addition, in item correlation to total score, items $4,5,8,12$, and 14 did not show item-total correlation; most of these were reverse-scored items. Cronbach's alpha item delete step 1-2-3 resulted in a Cronbach's alpha of 0.756 . Item 16 was also removed because it was reverse scored. When all item-total score correlation was reassessed, the sum of Cronbach's alpha increased to 0.759 . Due to the fact that these six items showed inconsistent results, they were not included in further analysis (Table 2).

Test-retest consistency was assessed by repeating the questionnaire at an interval of at least 7 days. To evaluate item agreement, intraclass correlation coefficient rho was applied to test agreement between baseline and retest scores. Rho and $P$-values were found as $r=0.564$ and $P<0.001$ (Table 2).

In our pulmonary arterial hypertension and heart failure patients, there was a moderate positive correlation between the modified eleven-item TSK Heart and the NHP ( $r=0.374$, $P<0.01)$. However, the total score did not correlate with 6MWT distance and IPAQ score.

Table I Demographic and clinical variables of the subjects

\begin{tabular}{lll}
\hline Variables (n=83) & Mean \pm SD & Min-max \\
\hline Age, years & $55.36 \pm 14.92$ & $18.00-80.00$ \\
Sex, $\mathrm{n}(\%)$ & & \\
Female & $37(44.6)$ & \\
Male & $46(55.4)$ & \\
Body weight, kg & $75.95 \pm 20.21$ & $47.00-182.00$ \\
Height, cm & $166.63 \pm 9.81$ & $150.00-186.00$ \\
VO, peak, $\mathrm{kg} / \mathrm{mL} / \mathrm{dk}$ & $15.62 \pm 4.09$ & $3.98-21.98$ \\
Body mass index, $\mathrm{kg} / \mathrm{m}^{2}$ & $27.12 \pm 5.62$ & $18.73-40.04$ \\
6MWT distance, $\mathrm{m}$ & $412.08 \pm 104.96$ & $100.00-600.00$ \\
IPAQ, MET & $826.50 \pm 966.77$ & $100.00-6,930.00$ \\
Nottingham Health Profile & $197.50 \pm 164.49$ & $0.00-560.17$ \\
Total TSK Heart score & $41.92 \pm 4.69$ & $30-53$ \\
\hline
\end{tabular}

Abbreviations: min, minimum; max, maximum; 6MWT, 6-minute walk test; IPAQ, International Physical Activity Questionnaire; TSK Heart, Tampa Scale of Kinesiophobia for Heart. 
Table 2 Reliability of the Tampa Kinesiophobia Scale for the Heart

\begin{tabular}{|c|c|c|c|c|c|c|}
\hline \multirow{2}{*}{$\begin{array}{l}\text { Item } \\
\text { number }\end{array}$} & \multicolumn{3}{|l|}{ Reliability (step I) } & \multirow{2}{*}{$\begin{array}{l}\text { Reliability (step 2) } \\
\text { Cronbach's alpha }\end{array}$} & \multirow{2}{*}{$\begin{array}{l}\text { Reliability (step 3) } \\
\text { Cronbach's alpha }\end{array}$} & \multirow{2}{*}{\begin{tabular}{|l|} 
Reliability \\
Test-retest
\end{tabular}} \\
\hline & Cronbach's alpha & Rho $(\rho)$ & Cronbach's alpha & & & \\
\hline & If item deleted-I & Question/total score & If item deleted-2 & If item deleted-2 & If item deleted-2 & Rho $(\rho)$ \\
\hline $\mathrm{I}$ & 0.577 & $0.658 * * / 0.000$ & 0.722 & 0.722 & 0.730 & $0.432 * / 0.000 * *$ \\
\hline 2 & 0.590 & $0.596 * * / 0.000$ & 0.743 & 0.743 & 0.748 & $0.553 * / 0.000 * *$ \\
\hline 3 & 0.608 & $0.497 * * / 0.000$ & 0.739 & 0.739 & 0.746 & $0.290 * * / 0.033 * *$ \\
\hline 4 & 0.662 & $0.149 / 0.178$ & & & & $0.525 * / 0.000 * *$ \\
\hline 5 & 0.658 & $0.148 / 0.182$ & & & & $0.398 * / 0.003 * *$ \\
\hline 6 & $0.57 \mid$ & $0.688 * * / 0.000$ & 0.716 & 0.716 & 0.718 & $0.392 * / 0.003 * *$ \\
\hline 7 & 0.626 & $0.385 * * / 0.000$ & 0.750 & 0.750 & 0.749 & $0.449 * / 0.001 * *$ \\
\hline 8 & 0.663 & $0.062 / 0.575$ & & & & $0.272 * * / 0.047 * *$ \\
\hline 9 & 0.582 & $0.64 \mid * * / 0.000$ & 0.720 & 0.720 & 0.722 & $0.533 * / 0.000 * *$ \\
\hline 10 & 0.632 & $0.314 * * / 0.004$ & 0.754 & 0.754 & 0.755 & $0.478 * / 0.000 * *$ \\
\hline 11 & 0.619 & $0.427 \mid * * / 0.000$ & $0.74 I$ & 0.741 & 0.744 & $0.458 * / 0.000 * *$ \\
\hline 12 & 0.683 & $-0.139 / 0.209$ & & & & $0.336 * / 0.013 * *$ \\
\hline 13 & 0.620 & $0.418 * * / 0.000$ & 0.745 & 0.745 & 0.752 & $0.460 * / 0.000 * *$ \\
\hline 14 & 0.642 & $0.246 * / 0.025$ & & & & $0.180 / 0.194$ \\
\hline 15 & 0.607 & $0.504 * * / 0.000$ & 0.730 & 0.730 & 0.733 & $0.282 * * / 0.039 * *$ \\
\hline 16 & 0.628 & $0.365 * * / 0.001$ & 0.759 & 0.759 & & $0.109 / 0.432$ \\
\hline 17 & 0.624 & $0.387^{* *} / 0.000$ & 0.745 & 0.745 & 0.749 & $0.231 / 0.093 * *$ \\
\hline Total & 0.640 & & 0.756 & 0.756 & 0.759 & $0.564 * / 0.000 * *$ \\
\hline
\end{tabular}

Notes: Reliability (step I) bold items indicate that item total correlation is low and should be extracted from the analysis. Test-retest score bold items indicate the items which do not have item test-retest agreement. $* P<0.05$; $* * P<0.00$ I.

\section{Exploratory factor analysis}

$\mathrm{KMO}$ values $>0.8$ can be considered good, that is, an indication that component or factor analysis will be useful for these variables. This usually occurs when most of the zeroorder correlations are positive. KMO values $<0.5$ occur when most of the zero-order correlations are negative. KMO values $<0.5$ require remedial action, either by deleting the offending variables or by including other variables related to the offenders. Perhaps the variables reflect responses to a questionnaire where some items were written so that high scores reflect the trait in question, while other items were structured so that low scores reflect the trait. Reverse coding the negatively worded items may remedy the low KMO value in this situation.

In this study, the results of the $\mathrm{KMO}(0.66)$ and Bartlett's test of sphericity $\left(a^{2}=239.61, P<0.001\right)$ justified continuing with the factor analysis. Both the scree plot and the inspection of the values suggested a four-factor solution that accounted for $64.9 \%$ of the exploratory variance. In the factor analysis, the first factor was fear of injury (three items: 1, 2, and 9), the second factor was dysfunctional self (three items: 6, 7, and 10), the third factor was perceived danger for heart problems (two items: 11 and 13), and the last factor was avoidance of exercise (three items: 3, 15, and 17). Since six items were deleted from the matrix, the items could not be grouped in the same subdivisions as the original TSK Heart. The rotated factor matrix is given in Table 3. Responding ratio for each item was $99 \%$ for the scale.
Table 3 Component matrix factor analysis

\begin{tabular}{|c|c|c|c|c|}
\hline & Factor I & Factor 2 & Factor 3 & Factor 4 \\
\hline & $\begin{array}{l}\text { Fear of } \\
\text { injury }\end{array}$ & $\begin{array}{l}\text { Dysfunctional } \\
\text { self }\end{array}$ & $\begin{array}{l}\text { Perceived } \\
\text { danger for } \\
\text { heart problem }\end{array}$ & $\begin{array}{l}\text { Avoidance } \\
\text { of exercise }\end{array}$ \\
\hline Item 2 & 0.792 & -0.086 & -0.124 & 0.237 \\
\hline Item I & 0.778 & 0.039 & 0.071 & 0.221 \\
\hline Item 9 & 0.724 & 0.252 & 0.465 & -0.201 \\
\hline Item 7 & 0.249 & 0.819 & -0.76 & -0.063 \\
\hline Item 10 & -0.195 & 0.670 & 0.163 & 0.270 \\
\hline Item 6 & 0.420 & 0.438 & 0.270 & 0.266 \\
\hline Item I3 & 0.100 & -0.089 & 0.857 & 0.108 \\
\hline Item II & -0.006 & 0.436 & 0.627 & 0.090 \\
\hline Item 15 & 0.190 & 0.064 & 0.261 & 0.757 \\
\hline Item 3 & 0.389 & 0.095 & -0.198 & 0.657 \\
\hline Item 17 & -0.075 & 0.339 & 0.342 & 0.433 \\
\hline
\end{tabular}

Note: Bold data indicates $P<0.05$.

\section{Discussion}

The purpose of this study was to examine the validity of the TSK for Heart by internal correlation coefficient and convergent validity based on the data gathering in the same study on NHP, IPAQ, and 6MWT and exploratory factor analysis.

Consistent with international guidelines, the cross-cultural adaptation required a process of forward and back translation, review by a committee of experts, and the testing of the prefinal version to ensure that the meaning of the original items was adequately conveyed by the idiomatic translation. ${ }^{16,17}$

Similar to other validity research of the TSK Heart, in our study, four reverse-coded items caused problems for our 
study population when completing the scale. ${ }^{24}$ In addition, Cronbach's alpha coefficient for the total score was lower than recommended results for health studies. Applying the if item deleted procedure increased Cronbach's alpha to an acceptable range (0.759). The offending items, which were reverse coded and showed low item-total correlations, were removed from further analysis. From the remaining 13 items of the TSK Heart, two more items (5 and 14) were excluded afterward because of low Cronbach's alpha values. They were worded negatively, making the question difficult to understand in our study population and confusing the person completing the scale. The items were "People do not take my medical conditions seriously enough" and "It really is not safe for someone in my condition to be physically active or to do exercise". Therefore, these items were also excluded from further analysis. Perhaps a better adaptation of items 5 and 14 would read "People take my medical condition seriously enough" and "It is fairly safe for someone in my condition to be physically active or to do exercise".

With all deleted items, the scale's item-total correlations were high, and Cronbach's alpha coefficient was within acceptable range at $0.759(>0.70)$. However, the Cronbach's alpha value was slightly lower than that found by Bäck et $\mathrm{al}^{1}$ with the TSK-SV Heart ( $\alpha=0.83$ in coronary artery bypass grafting patients). Test-retest reliability coefficients were acceptable $(\rho=0.564, P=0.001)$ for the total score. In short, the TSK Heart Turkish Version was valid when compared with the source text in Swedish. The internal correlation coefficient of 0.756 (95\% CI: 0.674-0.829) showed that form is valid.

Bäck et al performed binary logistic regression analysis to assess parallel forms validity with physical activity, IPAQ, and health-related quality of life as dependent variables. Each variable showed significant results, indicating that each of them is an independent determinant in logistic regression analysis. However, in our study, these variables were used to evaluate convergent validity. In convergent validity, significant correlations among the variables are important. To determine the proper analysis, Tukey's test of additivity was used to indicate the method of analysis as parametric or nonparametric. Due to the principle of additivity of this test and the fact that the other tests used to compare the results were parametric, all variables were evaluated by Pearson's correlation analysis.

Convergent validity testing by Pearson's correlation analysis revealed a statistically significant positive correlation between TSK Heart and NHP. Thus, kinesiophobia was found to be associated with quality of life. However, the
TSK Heart was not significantly correlated with the IPAQ or $6 \mathrm{MWT}$. This result indicated that kinesiophobia was not associated with activity level and is in contradiction with arguments by Vlaeyen and Linton, postulating that fear of pain leads to activity avoidance and therefore to functional disability. ${ }^{26}$ On the other hand, the IPAQ and 6MWT assess the behavioral constructs (avoidance and dysfunction) associated with physical activity, whereas the NHP evaluates the beliefs and perceptions as well as avoidance and dysfunction. This explains why the scale was found to correlate only with quality of life.

Exploratory factor analysis revealed that the four-factor model first described by Wiklund ${ }^{25}$ and Vlaeyen and Linton ${ }^{26}$ was the best fit to our study population using an elevenitem version of the scale. However, the eleven-item solution showed different distribution within the four-factor model. Items 1, 2, and 9 were under fear of injury; items 6, 7, and 10 were under dysfunctional self; items 11 and 13 were under perceived danger for heart problem; and items 3, 5, and 17 were under avoidance of activity. This result indicated that although our results best fit the four exploratory factor analysis, the results could not explain the factor analysis distribution of Kori et al. ${ }^{6}$ The subdimensions of the items showed different item-solution distributions in our study.

\section{Study limitations}

As a result, exploratory factor analysis demonstrated validity and four-factor model distribution for the TSK Heart Turkish Version. The scale provided standardization in data collection across the patients. However, the comprehensive data analysis might be affected by the patients' cultural behavior (eg, education and language structure). Therefore, further cultural adaptation may be a continuation of this research, although the eleven-item questionnaire is adequate to evaluate kinesiophobia related to cardiac conditions. It may be necessary to add some new items or adapt reverse-coded items with negation to make the scale more understandable.

\section{Conclusion}

This study describes the methods of cultural adaptation, exploratory factor analysis, and convergent validity analysis of the Turkish version of the TSK Heart, resulting in a four-factor, eleven-item solution. This model was the best fit, and the TSK Heart Turkish Version proved to be a valid questionnaire for the Turkish population, so kinesiophobic behavior of cardiac patients may be evaluated using this comprehensive scale. 


\section{Disclosure}

The authors report no conflicts of interest in this work.

\section{References}

1. Bäck M, Jansson B, Cider A, Herlitz J, Lundberg M. Validation of a questionnaire to detect kinesiophobia (fear of movement) in patients with coronary artery disease. J Rehabil Med. 2012;44(4):363-369.

2. Beswick AD, Rees K, West RR, et al. Improving uptake and adherence in cardiac rehabilitation: literature review. JAdv Nurs. 2005;49(5):538-555.

3. Philips H. Avoidance behaviour and its role in sustaining chronic pain. Behav Res Ther. 1987;25(4):273-279.

4. Pugh ME, Buchowski MS, Robbins IM, Newman JH, Hemnes AR. Physical activity limitation as measured by accelerometry in pulmonary arterial hypertension. Chest. 2012;142(6):1391-1398.

5. Alosco ML, Spitznagel MB, Cohen R, et al. Decreases in daily physical activity predict acute decline in attention and executive function in heart failure. J Card Fail. 2015;21(4):339-346.

6. Kori SH, Miller RP, Todd DD. Kinesiophobia: a new view of chronic pain behavior. Pain Manag. 1990;3(1):35-43.

7. Tunca Yılmaz Ö, Yakut Y, Uygur F, Uluğ N. Tampa Kinezyofobi Ölçeği'nin Türkçe versiyonu ve test-tekrar test güvenirliği. [Tampa Scale of Kinesiophobia Turkish Version Test-Retest Reliability]. Fizyoterapi Rehabilitasyon. 2011;22(1):44-49. Turkish.

8. Monticone M, Giorgi I, Baiardi P, Barbieri M, Rocca B, Bonezzi C. Development of the Italian version of the Tampa Scale of Kinesiophobia (TSK-I): cross-cultural adaptation, factor analysis, reliability, and validity. Spine (Phila Pa 1976). 2010;35(12):1241-1246.

9. Haugen AJ, Grøvle L, Keller A, Grotle M. Cross-cultural adaptation and validation of the Norwegian version of the Tampa Scale for Kinesiophobia. Spine (Phila Pa 1976). 2008;33(17):595-601.

10. Gómez-Pérez L, López-Martínez AE, Ruiz-Párraga GT. Psychometric properties of the Spanish version of the Tampa Scale for Kinesiophobia (TSK). J Pain. 2011;12(4):425-435.

11. ATS Committee on Proficiency Standards for Clinical Pulmonary Function Laboratories. ATS statement: guidelines for the six-minute walk test. Am J Respir Crit Care Med. 2002;166(1):111-117.

12. Sağlam M, Arikan H, Savci S, et al. International physical activity questionnaire: reliability and validity of the Turkish version. Percept Mot Skills. 2010;111(1):278-284.
13. Craig CL, Marshall AL, Sjöström M, et al. International physical activity questionnaire: 12-country reliability and validity. Med Sci Sports Exerc. 2003;35(8):1381-1395.

14. Hapidou EG, O’Brien MA, Pierrynowski MR, de las Heras E, Patel M, Patla T. Fear and avoidance of movement in people with chronic pain: psychometric properties of the 11-item Tampa Scale for Kinesiophobia (TSK-11). Physiother Can. 2012;64(3):235-241.

15. Küçükdeveci AA, McKenna SP, Kutlay S, GürselY, Whalley D, Arasil T. The development and psychometric assessment of the Turkish version of the Nottingham health profile. Int J Rehabil Res. 2000;23(1): 31-38.

16. Beaton D, Bombardier C, Guilleman F. Recommendations for the CrossCultural Adaptation of Health Status Measures. Rosemont, IL: American Academy of Orthopaedic Surgeons, Institute for Work and Health; 1998.

17. Beaton DE, Bombardier C, Guillemin F, Ferraz MB. Guidelines for the process of cross-cultural adaptation of self-report measures. Spine (Phila Pa 1976). 2000;25(24):3186-3190.

18. Newmark P. Approaches to Translation. New York; London: Prentice Hall MacMillan; 1995.

19. Clark ME, Kori SH, Brockel J. Kinesiophobia and chronic pain: psychometric characteristics and factor analysis of the Tampa Scale. Proceedings of the American Pain Society Annual Meeting. Vol. 15. 1996:77. American Pain Society, Chicago, IL, USA.

20. Şencan H. Sosyal ve Davranışsal Ölçümlerde Güvenilirlik ve Geçerlilik. [Reliability and validity of the Social and Behavioral Measurement]. 2005:105-107, 146, 249-257. Seçkin Publisher, Ankara, Turkey. Turkish.

21. Cerny CA, Kaiser HF. A study of a measure of sampling adequacy for factor-analytic correlation matrices. Multivariate Behav Res. 1997; 12(1):43-47.

22. Dziuban CD, Shirkey EC. When is a correlation matrix appropriate for factor analysis? Psychol Bull. 1974;81(6):358-361.

23. Kaiser HF. A second generation Little Jiffy. Psychometrika. 1970;35(4): 401-415.

24. Shafazand S, Goldstein MK, Doyle RL, Hlatky MA, Gould MK. Healthrelated quality of life in patients with pulmonary arterial hypertension. Chest. 2004;126(5):1452-1459.

25. Wiklund L. Nottingham health profile - a measure of health-related quality of life. Scand J Prim Health Care. 1990;1:15-18.

26. Vlaeyen JW, Linton SJ. Fear - avoidance model of chronic musculoskeletal pain: 12 years on. Pain. 2012;153(6):1144-1147.
Journal of Pain Research

\section{Publish your work in this journal}

The Journal of Pain Research is an international, peer reviewed, open access, online journal that welcomes laboratory and clinical findings in the fields of pain research and the prevention and management of pain. Original research, reviews, symposium reports, hypothesis formation and commentaries are all considered for publication.

\section{Dovepress}

The manuscript management system is completely online and includes a very quick and fair peer-review system, which is all easy to use. Visit http://www.dovepress.com/testimonials.php to read real quotes from published authors. 